\title{
Displacement of a peripherally inserted central catheter after injection of contrast media
}

\author{
Masayuki Akatsuka 다, ${ }^{1}$ Hiroomi Tatsumi, ${ }^{1}$ Naoya Yama, ${ }^{2}$ Yoshiki Masuda ${ }^{1}$
}

${ }^{1}$ Department of Intensive Care Medicine, Sapporo Medical University School of Medicine, Sapporo, Hokkaido, Japan ${ }^{2}$ Department of Diagnostic Radiology, Sapporo Medical University School of Medicine, Sapporo, Hokkaido, Japan

\section{Correspondence to}

Dr Masayuki Akatsuka; maasa_aka@icloud.com

Accepted 15 September 2021

\section{Check for updates}

(c) BMJ Publishing Group Limited 2021. No commercial re-use. See rights and permissions. Published by BMJ.

\begin{tabular}{|l|}
\hline To cite: Akatsuka M, \\
Tatsumi H, Yama N, et al. BMJ \\
Case Rep 2021;14:e246068. \\
doi:10.1136/bcr-2021- \\
246068 \\
\hline
\end{tabular}

\section{DESCRIPTION}

A peripherally inserted central catheter (PICC) was inserted through the right basilic vein and placed within the superior vena cava of a patient for fluid and medication administration during postoperative management of bladder cancer.

Following the development of sepsis, contrastenhanced CT was performed to detect infectious foci. The tip of the PICC appeared displaced into the internal jugular vein in the early phase and was placed on the superior vena cava in the delayed phase (figure 1). In the second CT scan performed 2 days later, the tip of the PICC had moved again in the early phase, resulting in it being placed on the superior vena cava in the delayed phase (figure 2). The rates of contrast injection for the first and second CT scans were $4.1 \mathrm{~mL} / \mathrm{s}$ and $4.7 \mathrm{~mL} / \mathrm{s}$, respectively.

The power PICC is approved by the US Food and Drug Administration for power injection of contrast medium in adults and children. However, migrating PICC lines following power injection of contrast media has been reported at an estimated rate of $8.2 \%-15.4 \% .^{12}$

Based on our experience, we present some suggestions for using power PICC as the preferred injection line of contrast media. First, we need to consider the flow rate of the contrast media. Newton's third law of motion states that when one object exerts a force on a second object, the second object exerts a force that is equal in magnitude and opposite in direction on the first object. The movement of

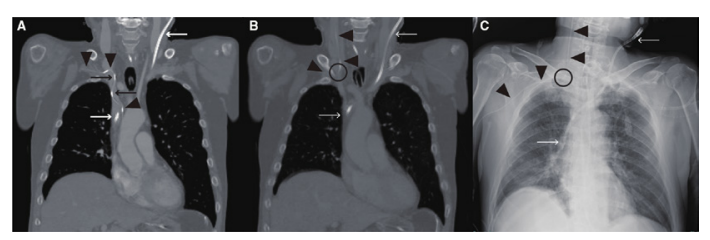

Figure 1 Images from the first $\mathrm{CT}$ and chest radiography. (A) Early phase: the tip of the PICC is moving in the superior vena cava. The black arrow indicates that the PICC is undulating in the superior vena cava. (B) Delayed phase: the tip of the PICC is placed on the internal jugular vein. (C) Chest radiography after the CT image: the tip of the PICC is placed on the internal jugular vein. The black triangles indicate the position of the PICC. The black circle indicates that the PICC is directed into the right internal jugular vein. The white arrows indicate the position of the FDL catheter inserted through the left internal jugular vein and placed in the superior vena cava as vascular access for CRRT. PICC, peripherally inserted central catheters; FDL, flexible double lumen; CRRT, continuous renal replacement therapy.

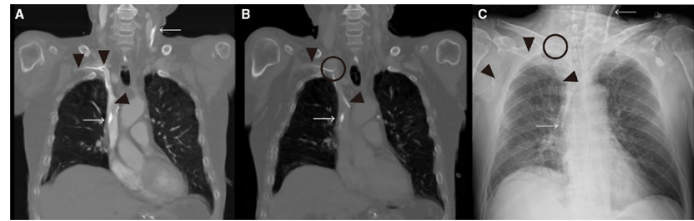

Figure 2 Images from the second CT and chest radiography. (A) Early phase: the tip of the PICC has moved into the superior vena cava. (B) Delayed phase: the tip of the PICC is placed on the superior vena cava. (C) Chest radiography after CT imaging: the tip of the PICC is placed on the superior vena cava with a loop at the beginning of the internal jugular vein. The black triangles indicate the position of the PICC. The black circle indicates that the PICC forms a loop at the beginning of the internal jugular vein. The white arrows indicate the position of the FDL catheter inserted through the left internal jugular vein and placed in the superior vena cava as vascular access for CRRT. PICC, peripherally inserted central catheters; FDL, flexible double lumen; CRRT, continuous renal replacement therapy.

the PICC at the opposite site can be minimised to reduce the energy on the tip of the PICC from the injection of contrast. Second, warm contrast media should be used. Poiseuille's law shows that the flow rate through a tubular structure is directly affected by the length and diameter of the catheter, medium viscosity and injection rate. Warm contrast medium could reduce resistance through the PICC because viscosity is inversely proportional to temperature. Third, we need to place the tip of the PICC in a slightly deeper position within the superior vena

\section{Patient's perspective}

We are very pleased with all the kindness and care we received in the hospital. In the end, we hope that doctors all over the world have learned something from my father's case.

\section{Learning points}

- The peripherally inserted central catheter (PICC) line can be used as the injection site of contrast media during CT studies. Patients are more comfortable because an additional peripheral venous route is not required.

- We should be careful when identifying the location of the tip of the PICC following the injection of contrast media. 
cava: zone A, the lower half of the superior vena cava, and the upper right atrium. This could prevent the tip of the PICC from becoming misplaced after the injection of contrast media, although the tip still moves slightly within a vessel. Fourth, we need to check the position of the tip of the PICC after injection. If necessary, interventions such as removal or replacement of the catheter may be required because of malpositioning of the catheter tip.

Contributors MA and HT contributed to the management of the patient. MA wrote the first draft. NY reviewed the CT findings. YM reviewed the manuscript. All authors read and approved the final version of the manuscript.

Funding The authors have not declared a specific grant for this research from any funding agency in the public, commercial or not-for-profit sectors.
Competing interests YM received lecture fees from MSD K.K. and Japan Blood Product and an industry-academia collaborative research grant from JIMRO Co., Ltd. $\mathrm{HT}$ received lecture fees from TSUMURA \& $\mathrm{CO}$.

Patient consent for publication Consent obtained from next of kin.

Provenance and peer review Not commissioned; externally peer reviewed.

\section{ORCID iD}

Masayuki Akatsuka http://orcid.org/0000-0003-0065-9721

\section{REFERENCES}

1 Lozano LAS, Marn C, Goodman LR. Power injectable peripherally inserted central venous catheter lines frequently FLIP after power injection of contrast. J Comput Assist Tomogr 2012;36:427-30

2 Morden P, Sokhandon F, Miller L, et al. The role of saline flush injection rate in displacement of CT-injectable peripherally inserted central catheter tip during power injection of contrast material. AJR Am J Roentgenol 2014;202:W13-18.

Copyright 2021 BMJ Publishing Group. All rights reserved. For permission to reuse any of this content visit https://www.bmj.com/company/products-services/rights-and-licensing/permissions/

BMJ Case Report Fellows may re-use this article for personal use and teaching without any further permission.

Become a Fellow of BMJ Case Reports today and you can:

- Submit as many cases as you like

Enjoy fast sympathetic peer review and rapid publication of accepted articles

Access all the published articles

Re-use any of the published material for personal use and teaching without further permission

Customer Service

If you have any further queries about your subscription, please contact our customer services team on +44 (0) 2071111105 or via email at support@bmj.com.

Visit casereports.bmj.com for more articles like this and to become a Fellow 